\title{
Effects of onapristone, tamoxifen and ICI 182780 on uterine prostaglandin production and luteal function in nonpregnant guinea-pigs
}

\author{
N. L. Poyser \\ Department of Pharmacology, University of Edinburgh Medical School, 1 George Square, \\ Edinburgh EH8 9JZ, UK
}

\begin{abstract}
Onapristone (a progesterone antagonist) or ICI 182780 (an oestrogen antagonist) administered to guinea-pigs on days 11-14 of the cycle significantly reduced uterine PGF $_{2 \alpha}$ output on day 15. Concentrations of progesterone in plasma of onapristone-treated and ICI 182780treated guinea-pigs were still high on day 15 indicating that luteal regression had been prevented. These findings indicate that progesterone and oestradiol are necessary for increased $\mathrm{PGF}_{2 \alpha}$ production by the uterus towards the end of the cycle, and support the hypothesis that oestradiol acting on a progesterone-primed uterus is the physiological stimulus for increased uterine $\mathrm{PGF}_{2 \alpha}$ synthesis and release in guinea-pigs. The capacity of the endometrium to synthesize PGF $2 \alpha$ on day 15 was reduced by treatment with ICI 182780 and, unexpectedly, by treatment with onapristone, indicating that onapristone may also be antagonizing the release or action of oestradiol in some way. Tamoxifen was an agonist in guinea-pigs since it induced vaginal opening. It had no inhibitory effect on uterine $\mathrm{PGF}_{2 \alpha}$ output and did not delay luteal regression when administered between days 11 and 14 of the cycle. However, it redirected PG synthesis in homogenates of endometrium and myometrium from $\mathrm{PGI}_{2}$ (as indicated by 6-keto-PGF ${ }_{1 \alpha}$ ) to $\mathrm{PGF}_{2 \alpha}$. The output of 6-keto- $\mathrm{PGF}_{1 \alpha}$ from the uterus of day 15 guinea-pigs was reduced following tamoxifen treatment, but the high output of $\mathrm{PGF}_{2 \alpha}$ from the uterus was not affected.
\end{abstract}

\section{Introduction}

Prostaglandin $\mathrm{F}_{2 \alpha}\left(\mathrm{PGF}_{2 \alpha}\right)$ produced by the uterus is responsible for regression of the corpora lutea in the ovary of guineapigs (see Horton and Poyser, 1976; Poyser, 1981). Oestradiol administered to ovariectomized guinea-pigs maintained on progesterone stimulates uterine $\mathrm{PGF}_{2 \alpha}$ output (Blatchley and Poyser, 1974; Poyser, 1983a). During the oestrous cycle, oestradiol secretion from the ovary increases from day 10 (Joshi $e t$ al., 1973); this precedes the increase in $\mathrm{PGF}_{2 a}$ secretion from the uterus by $24 \mathrm{~h}$ (Blatchley et al., 1972; Earthy et al., 1975; Antonini et al., 1976). Oestradiol acting on a progesteroneprimed uterus therefore appears to be the physiological stimulus for increased $\mathrm{PGF}_{2 \alpha}$ production by guinea-pig uterus (particularly the endometrium) towards the end of the oestrous cycle, especially as oxytocin has no stimulatory effect on endometrial $\mathrm{PGF}_{2 \alpha}$ synthesis in guinea-pigs (Poyser and Brydon, 1983; Riley and Poyser, 1987). If this is so, appropriate steroid receptor antagonists should prevent the stimulation of uterine $\mathrm{PGF}_{2 \alpha}$ synthesis and release towards the end of the cycle, and thereby should delay luteal regression. Consequently, the effects of onapristone (a progesterone antagonist), tamoxifen and ICI 182780 (oestrogen antagonists) on uterine $\mathrm{PGF}_{2 a}$ production and luteal function in guineapigs were investigated.

Received 20 October 1992.

\section{Materials and Methods}

Twenty-five virgin guinea-pigs, weighing $650-850 \mathrm{~g}$, were examined daily and a vaginal smear was taken when the vagina was perforate. Day 1 of the cycle was defined as the day preceding the post-ovulatory influx of leucocytes when cornification was at a maximum. All guinea-pigs had exhibited at least two cycles of normal duration (16 to 17 days) before being treated as described in the following experiments. The animals were killed by stunning and incising the neck on the day after the last day of treatment.

\section{Experiment 1: effects of onapristone and tamoxifen}

Guinea-pigs were injected s.c. once a day from days 11 to 14 of the cycle with $1 \mathrm{ml}$ peanut oil containing $5 \%$ benzyl alcohol (control vehicle), $10 \mathrm{mg}$ onapristone, or $10 \mathrm{mg}$ tamoxifen (five animals per treatment). The uteri were removed on day 15 . One uterine horn from each uterus was superfused with Krebs solution ( $5 \mathrm{ml} \mathrm{min}^{-1}$; for composition see Mitchell et al., 1977) at $37^{\circ} \mathrm{C}$ and pre-gassed with $5 \% \mathrm{CO}_{2}-95 \% \mathrm{O}_{2}$. Samples of superfusate were collected for 10-min periods between 0-10 and $60-70 \mathrm{~min}$ of superfusion. The other uterine horn was divided into endometrium and myometrium by cutting away small pieces of endometrium from the myometrium. This technique separates the two tissues by $>85 \%$ (Leaver and Poyser, 1981). Both tissue types were homogenized separately in $10 \mathrm{ml}$ 
Krebs solution and were incubated at $37^{\circ} \mathrm{C}$ for $60 \mathrm{~min}$. After superfusion or incubation, the $\mathrm{pH}$ of the samples of superfusates and of the incubates were lowered to 4.0 with 1 mol $\mathrm{HCl} \mathrm{l}^{-1}$, and the PGs were extracted by shaking twice with ethyl acetate (50 and $20 \mathrm{ml}$ for the superfusates and incubates, respectively). The two ethyl acetate extracts obtained from each sample were combined and evaporated to dryness at $50^{\circ} \mathrm{C}$ on a rotary evaporator. The recoveries of $\mathrm{PGF}_{2 \alpha}$ and $\mathrm{PGE}_{2}$ are $>90 \%$ and the recovery of 6-keto-PGF ${ }_{1 \alpha}$ is $>80 \%$ by this method (Poyser and Scott, 1980; Swan and Poyser, 1983). The results are not corrected for recovery. The amounts of $\mathrm{PGF}_{20^{\prime}} \mathrm{PGE}_{2}$ and 6-keto-PGF ${ }_{1 \alpha}$ present in each sample were measured by radioimmunoassay using antibodies raised in this laboratory; the crossreactivities have been reported elsewhere (Poyser, 1987). The inter- and intra-assay coefficients of variation were $<11.8 \%$. The detection limit was $10-30 \mathrm{pg}$ per assay tube.

At the time of removing the uterus, a sample of peripheral blood was collected into a heparinized $\left(20 \mathrm{U} \mathrm{ml}^{-1}\right)$ syringe. The blood was centrifuged at $2500 \mathrm{~g}$ for $15 \mathrm{~min}$, and the plasma was withdrawn and stored at $-20^{\circ} \mathrm{C}$. Progesterone in the plasma samples was measured as described by Poyser and Horton (1975), using an antibody raised in this laboratory; the crossreactivities have been reported elsewhere (Poyser, 1983b, 1984). The intra-assay coefficient of variation was $9.5 \%$, and all the samples were measured in one assay. The detection limit was 40 pg per assay tube.

\section{Experiment 2: effects of ICI 182780}

Guinea-pigs were injected s.c. once a day from days 11 to 14 of the cycle with $0.8 \mathrm{ml} 5 \%$ benzyl alcohol in peanut oil alone (controls) or containing $4 \mathrm{mg}$ ICI 182780 (five animals per group). The uteri were removed on day 15 and treated as in Expt 1. The amounts of PGF ${ }_{2 \alpha^{\prime}} \mathrm{PGE}_{2}$ and 6-keto-PGF ${ }_{1 \alpha}$ present in the extracts obtained were measured by radioimmunoassay. The inter- and intra-assay coefficients of variation were $<12 \%$, and the detection limits were $20-30$ pg PG per assay tube.

Progesterone was measured in a peripheral plasma sample, obtained from each guinea-pig at the time of removing the uterus, by radioimmunoassay as outlined in Expt 1 . The intraassay coefficient of variation was $10.1 \%$, and all the samples were measured in one assay. The detection limit was $40 \mathrm{pg}$ per assay tube.

\section{Statistical tests}

Results were analysed by the Student's $t$ test or, if the variances of the two groups were significantly different by the variance ratio $F$ test, by a modified $t$ test for unequal variances (see Steel and Torrie, 1980).

\section{Results}

$\mathrm{PGF}_{2 \alpha}$ was the major PG released, together with lesser quantities of $\mathrm{PGE}_{2}$ and 6-keto-PGF ${ }_{1 \alpha}$, from the uterus superfused in vitro from day 15 control guinea-pigs. These outputs of $\mathrm{PGF}_{2 \alpha^{\prime}}$ $\mathrm{PGE}_{2}$ and 6-keto-PGF $1 \alpha$ fell significantly $(P<0.05)$ between

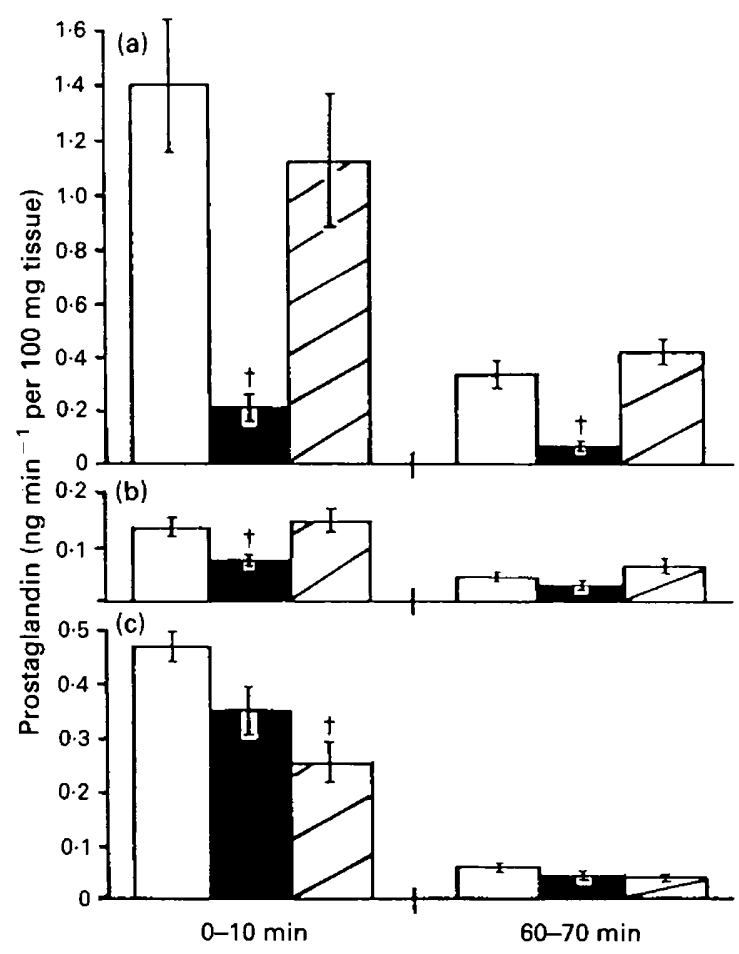

Fig. 1. Mean ( $\pm \mathrm{SEM}, n=5$ ) outputs of (a) $\mathrm{PGF}_{2 \alpha^{\prime}}$ (b) $\mathrm{PGE}_{2}$ and (c) 6-keto-PGF ${ }_{10}$ from the day 15 uterus of $(\square)$ control, ( $\square$ ) onapristonetreated and $(\square)$ tamoxifen-treated guinea-pigs when superfused in vitro during the periods (i) 0-10 min and (ii) 60-70 min. †Significantly $(P<0.05)$ lower than the control output of the same PG during the same period.

the first $(0-10 \mathrm{~min})$ and second $(60-70 \mathrm{~min})$ periods of superfusion (Figs $I$ and 2). The treatment of guinea-pigs with onapristone between days 11 and 14 of the cycle significantly $(P<0.05)$ reduced the outputs from the uterus of $\mathrm{PGF}_{2 \alpha}$ on day 15 during both periods of superfusion, and of $\mathrm{PGE}_{2}$ during the first period of superfusion. Onapristone had no significant effect on the output of 6-keto-PGF $\mathrm{PG}_{1 \alpha}$ during either superfusion period (Fig. 1). Tamoxifen administered to guinea-pigs between days 11 and 14 of the cycle had no effect on the uterine outputs on day 15 of $\mathrm{PGF}_{2 \alpha}$ and $\mathrm{PGE}_{2}$, but significantly $(P<0.05)$ reduced the output of 6-keto-PGF $\mathrm{F}_{1 \alpha}$ during the first but not the second period of superfusion (Fig. 1).

The treatment of guinea-pigs with ICI 182780 on days 11 to 14 of the cycle significantly $(P<0.05)$ reduced the outputs of $\mathrm{PGF}_{2 \alpha}$ and $\mathrm{PGE}_{2}$ from the day 15 uterus during both periods of superfusion. ICI 182780 treatment had no effect on the output of 6-keto-PGF ${ }_{1 \alpha}$ from the day 15 uterus during either period of superfusion (Fig. 2).

$\mathrm{PGF}_{2 \alpha}$ and 6-keto-PGF ${ }_{1 \alpha}$ were the major PGs synthesized by homogenates of day 15 endometrium and myometrium, respectively, although the endometrium also synthesized significant quantities of 6-keto-PGF $\mathrm{PGE}_{2}$. $\mathrm{PG}_{2}$ synthesized in smaller quantities by both tissues (Figs 3 and 4). Onapristone administered between days 11 and 14 of the cycle significantly $(P<0.05)$ reduced the amount of $\mathrm{PGF}_{2 \alpha}$ synthesized by homogenates of the day 15 endometrium, without significantly affecting the amounts of $\mathrm{PGE}_{2}$ and 6-keto-PGF ${ }_{1 \alpha}$ synthesized 


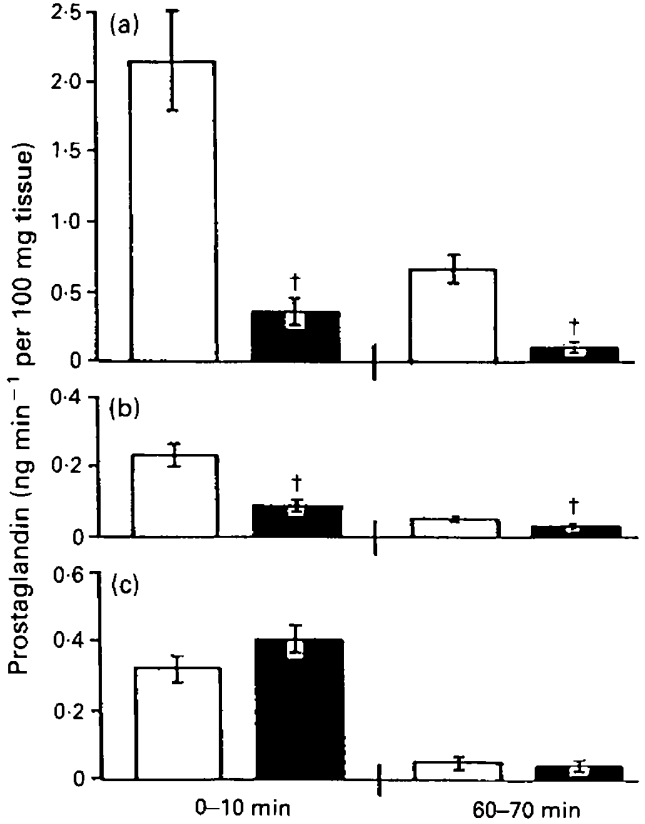

Fig. 2. Mean ( \pm SEM, $n=5$ ) amounts of (a) $\mathrm{PGF}_{2 a^{\prime}}$ (b) $\mathrm{PGE}_{2}$ and (c) 6keto-PGF from the day 15 uterus of $(\square)$ control and ( $\square$ ) ICI 182780treated guinea-pigs when superfused in vitro during the periods (i) $0-10 \mathrm{~min}$ and (ii) 60-70 min. †Significantly $(P<0.05$ ) lower than the control value for the same $\mathrm{PG}$ during the same time period.

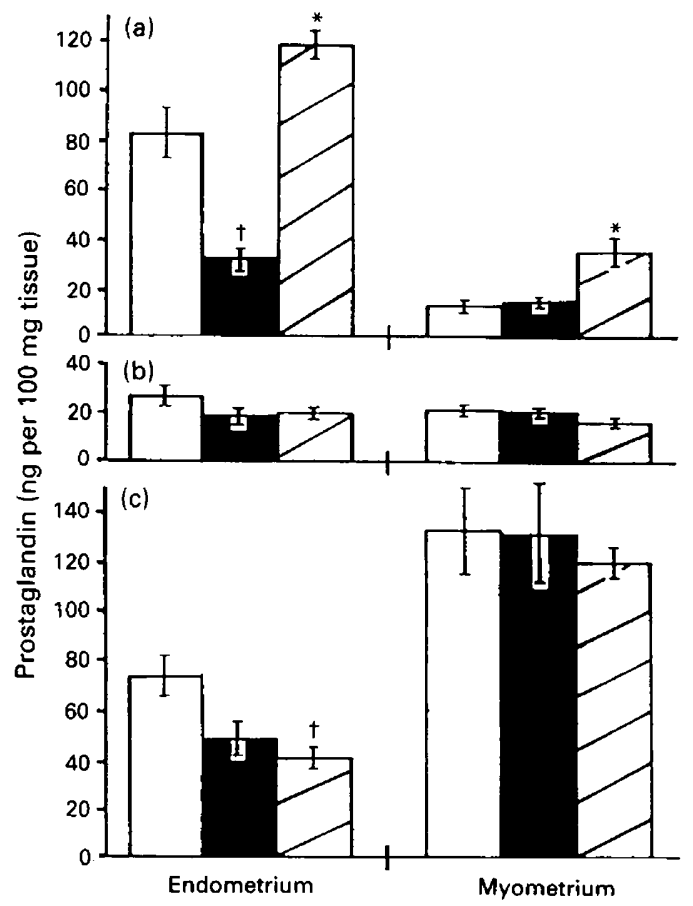

Fig. 3. Mean ( $\pm \mathrm{SEM}, n=5$ ) amounts of (a) $\mathrm{PGF}_{2 \alpha^{\prime}}$ (b) $\mathrm{PGE}_{2}$ and (c) 6-keto-PGF ${ }_{1 \alpha}$ synthesized during $1 \mathrm{~h}$ by homogenates of day 15 endometrium and myometrium from $(\square)$ control, ( $\square$ ) onapristone-treated and $(\square)$ tamoxifen-treated guinea-pigs. †Significantly $(P<0.05)$ lower than the control value for the same $P G$ in the same tissue. *Significantly $(P<0.05)$ higher than the control value for the same PG in the same tissue.

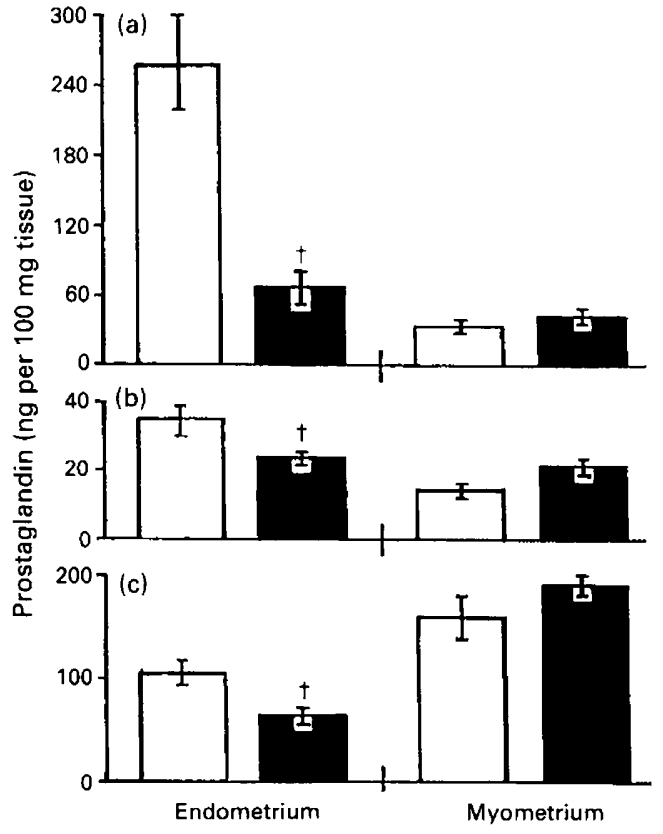

Fig. 4. Mean ( $\pm \mathrm{SEM}, n=5$ ) amounts of (a) $\mathrm{PGF}_{2 \alpha^{\prime}}$ (b) $\mathrm{PGE}_{2}$ and (c) 6-keto-PGF ${ }_{1 \alpha}$ synthesized during $\mathrm{I} h$ by homogenates of endometrium and myometrium from ( $\square$ ) control and ( $\square$ ) ICI 182780-treated guinea-pigs on day 15 of the cycle. + Significantly $(P<0.05)$ lower than the control value for the same PG in the same tissue.

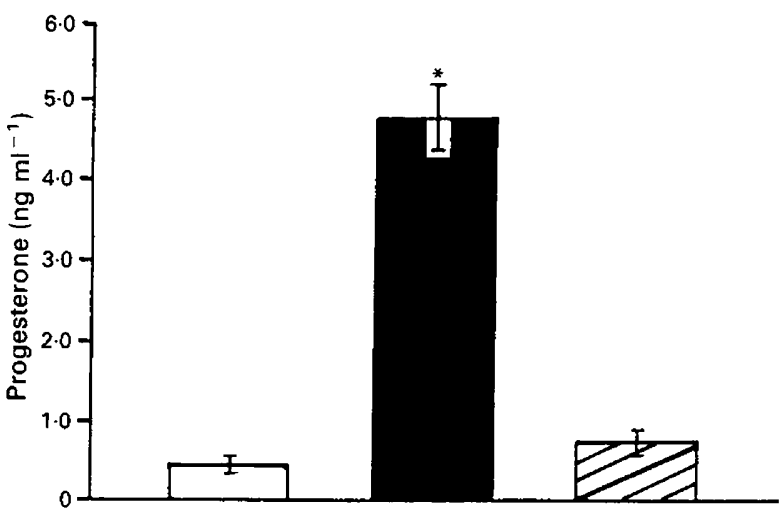

Fig. 5. Mean ( $\pm \operatorname{SEM}, n=5$ ) concentrations of progesterone in the peripheral plasma of $(\square)$ control, ( $\square$ ) onapristone-treated and ( $\square$ ) tamoxifen-treated guinea-pigs on day 15 of the cycle. *Significantly $(P<0.05)$ higher than the control and tamoxifen-treated values.

(although the synthesis of both PGs tended to be reduced; Fig. 3). Onapristone treatment had no effect on the amounts of the three PGs synthesized by homogenates of day 15 myometrium (Fig. 3). Tamoxifen administered between days 11 and 14 of the cycle significantly $(P<0.05)$ increased the amount of $\mathrm{PGF}_{2 \alpha}$ synthesized and significantly $(P<0.05)$ decreased the amount of 6-keto-PGF ${ }_{1 \alpha}$ synthesized by homogenates of the day 15 endometrium, without affecting $\mathrm{PGE}_{2}$ synthesis (Fig. 3). Tamoxifen administration significantly $(P<0.05)$ increased the amount of 6-keto-PGF ${ }_{1 \alpha}$ synthesized by homogenates of day 15 endometrium, without significantly affecting the amounts of 

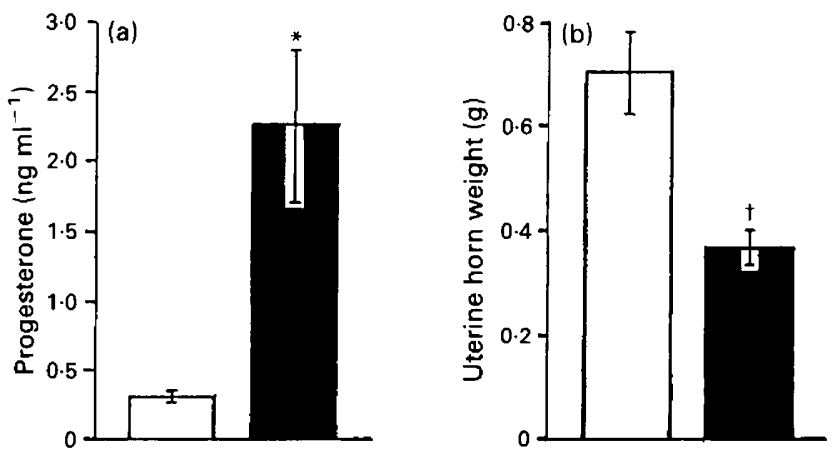

Fig. 6. Mean ( $\pm \operatorname{SEM}, n=5$ ) (a) concentrations of progesterone in peripheral plasma, and (b) uterine horn weight in ( $\square$ ) control and ( $\square$ ) ICI 182780-treated guinea-pigs on day 15 of the cycle. *Significantly $(P<0.05)$ higher than the corresponding control value. $\dagger$ Significantly $(P<0.05)$ lower than the corresponding control value.

$\mathrm{PGE}_{2}$ and 6-keto-PGF ${ }_{1 \alpha}$ synthesized (although these were slightly depressed).

Treatment with ICI 182780 from days 11 to 14 of the cycle significantly $(P<0.05)$ reduced the amounts of $\mathrm{PGF}_{2 \alpha^{\prime}} \mathrm{PGE}_{2}$ and 6-keto- $\mathrm{PGF}_{1 \alpha}$ synthesized by homogenates of the day 15 endometrium, with $\mathrm{PGF}_{2 \alpha}$ synthesis being particularly affected (Fig. 4). ICI 182780 treatment had no significant effect on the amounts of $\mathrm{PGF}_{2 \alpha}, \mathrm{PGE}_{2}$ and 6-keto-PGF ${ }_{1 \alpha}$ synthesized by homogenates of day 15 myometrium (Fig. 4).

Concentrations of progesterone in peripheral plasma were typically low $\left(<1 \mathrm{ng} \mathrm{ml}^{-1}\right)$ on day 15 in control and tamoxifentreated guinea-pigs, but were significantly $(P<0.05)$ increased in guinea-pigs treated with onapristone and ICI 182780 (Figs 5 and 6a). Tamoxifen caused the vagina to open after 2-3 days of treatment, which is in agreement with a previous report (Furr and Jordan, 1984).

Mean ( \pm SEM, $n=5$ ) uterine horn weights of the guinea-pigs used in Expt 1 were $0.662 \pm 0.094,0.509 \pm 0.018$, and $0.636 \pm$ $0.022 \mathrm{~g}$ in the control, onapristone-treated, and tamoxifen-treated animals, respectively. These values did not differ significantly. In Expt 2, the uterine horn weight was significantly $(P<0.05)$ lower in ICI 182780-treated guinea-pigs than in control guinea-pigs (Fig. 6b).

\section{Discussion}

If oestradiol acting on a progesterone-primed uterus is the physiological stimulus for increasing uterine $\mathrm{PGF}_{2 \alpha}$ synthesis and release in guinea-pigs, inhibiting the effect of each steroid with a receptor antagonist should reduce uterine $\mathrm{PGF}_{2 \alpha}$ output and delay luteal regression. Onapristone (a progesterone antagonist) administered to guinea-pigs between days 11 and 14 of the cycle inhibited uterine $\mathrm{PGF}_{2 a}$ output and extended luteal lifespan (as indicated by peripheral plasma progesterone concentrations) when examined on day 15. Consequently, endogenous progesterone appears to be essential for the increase in uterine $\mathrm{PGF}_{2 \alpha}$ synthesis and release after day 11 of the cycle. However, since maximum uterine $\mathrm{PGF}_{2 a}$ output occurs when plasma progesterone concentrations are at their lowest, this inverse correlation supports a 'priming role' for progesterone. Onapristone also reduced uterine $\mathrm{PGE}_{2}$ output (which indicates that $\mathrm{PGE}_{2}$ may be a by-product of $\mathrm{PGF}_{2 a}$ synthesis), but had no significant effect on 6-keto-PGF ${ }_{1 \alpha}$ output. This is in agreement with previous findings (Riley and Poyser, 1987, 1990) which showed that endometrial $\mathrm{PGF}_{2 \alpha}$ and $\mathrm{PGI}_{2}$ (as indicated by 6-keto-PGF ${ }_{1 \alpha}$ ) syntheses are controlled independently.

The decrease in uterine $\mathrm{PGF}_{2 a}$ output induced by onapristone is not due to increased PG metabolism, since the increases in peripheral plasma concentrations of 13,14-dihydro-15-keto$\mathrm{PGF}_{2 \alpha}$ in guinea-pigs towards the end of the cycle (and which are indicative of increased uterine $\mathrm{PGF}_{2 a}$ secretion) are prevented by onapristone treatment. Luteal function is also prolonged (Qing et al., 1989).

During the cycle, the amounts of $\mathrm{PGF}_{2 \alpha}$ synthesized by homogenates of guinea-pig endometrium increase 2.2-fold between days 7 and 13 of the cycle as ovarian oestradiol output increases, but this increase reaches 4.4 -fold at the end of the cycle after plasma progesterone concentrations have fallen (Poyser, 1983b). In ovariectomized guinea-pigs, oestradiol administered alone increases endometrial $\mathrm{PGF}_{2 a}$ synthesizing capacity 3.2 -fold, but when progesterone treatment precedes oestradiol administration the capacity of the endometrium to synthesize PGF $_{2 a}$ increases only 1.7-fold (Poyser, 1983b). These differences are not due to changes in PG metabolism since, in the absence of $\mathrm{NAD}^{+}$, metabolism of PGs by the guinea-pig uterus is low $(<5 \%$; Poyser, 1979), nor are they due to lack of arachidonic acid since, during the homogenization process, large amounts of free arachidonic acid are released (Mitchell et al., 1977). As prostaglandin endoperoxide synthase exhibits a self-catalysed destruction during the synthesis of PGs within the period studied (Lands ef al., 1973), the increases in the amounts of $\mathrm{PGF}_{2 \alpha}$ synthesized by homogenates of guinea-pig endometrium during the cycle or following oestradiol treatment are due to an increase in the amounts of enzymes that synthesize PGs that are present. Oestradiol stimulates the synthesis of these enzymes, but progesterone attenuates this stimulatory effect. However, oestradiol acting on a progesterone-primed uterus stimulates endometrial synthesis and release from the intact tissue, so this increase is not directly due to an increase in the amounts of $\mathrm{PGF}_{2 \alpha}$ synthesizing enzymes present in the endometrium. Consequently in the present study, whereas onapristone prevents the stimulation of endometrial $\mathrm{PGF}_{2 \alpha}$ synthesis and secretion, it might be expected to increase the amounts of enzymes that synthesize $\mathrm{PGF}_{2 \alpha}$ in the endometrium as the attenuating effect of progesterone on this stimulatory action of oestradiol should be prevented. However, this did not occur since onapristone treatment reduced the amounts of $\mathrm{PGF}_{2 \alpha}$ synthesized by the day 15 endometrial homogenates by $68 \%$. The amounts of $\mathrm{PGE}_{2}$ and 6-keto-PGF $\mathrm{PG}_{1 \alpha}$ synthesized by homogenates of day 15 endometrium following onapristone treatment tended also to be reduced, so that in these animals the total amount of $\mathrm{PGF}_{2 \alpha^{\prime}} \mathrm{PGE}_{2}$ and 6-keto-PGF ${ }_{1 \alpha}$ synthesized by endometrial homogenates was reduced by $50 \%$.

It would seem that onapristone may also be inhibiting the action of oestradiol either by reducing ovarian oestradiol output (possibly as a consequence of maintaining plasma progesterone concentrations at a high value), or by some action of onapristone on the uterus. Onapristone did not reduce the uterine horn weight of day 15 guinea-pigs, which suggests that it is not inhibiting the action of oestradiol directly (i.e. at the oestrogen receptor level). In ovariectomized rabbits treated with 
oestradiol alone or with onapristone, there is a dose-dependent inhibition by onapristone of oestradiol-induced gland formation in the endometrium, and also degenerative changes occur in the glandular epithelial cells within the endometrium. These changes produced by onapristone appear to be mediated by progesterone receptors since the additional administration of progesterone prevents these actions of onapristone (Chwalisz et al., 1991). Since many studies in a variety of species have indicated that the glandular epithelial cells are the main source of $\mathrm{PGF}_{2 \alpha}$ and are the cells acted upon by steroid hormones, and if similar inhibitory and degenerative changes affect glandular epithelial cells in the endometrium of guinea-pigs as in rabbits following onapristone treatment, this may explain why onapristone has an inhibitory effect on the amounts of $\mathrm{PGF}_{2 \alpha}$ synthesized by homogenates of the endometrium at the end of the cycle. However, as plasma concentrations of progesterone remained high in the onapristone-treated guinea-pigs and progesterone prevented the degenerative changes induced in rabbit endometrium by onapristone, another reason may have to be sought to explain why onapristone reduced the PG synthesizing capacity of guinea-pig endometrium. The mechanism by which onapristone reduces endometrial PG synthesizing capacity merits further study.

Tamoxifen was an agonist in guinea-pigs as it induced vaginal opening within 2 to 3 days after the start of treatment, and it did not decrease uterine weight. Tamoxifen had no inhibitory effect on uterine $\mathrm{PGF}_{2 \alpha}$ output, and did not prevent luteal regression from occurring at the normal time. Tamoxifen significantly increased the amounts of $\mathrm{PGF}_{2 \alpha}$ synthesized by homogenates of the endometrium and myometrium, and significantly reduced the amount of 6-keto-PGF $1 \alpha$ synthesized by homogenates of the endometrium. The amount of 6-keto- $\mathrm{PGF}_{1 a}$ synthesized by homogenates of the myometrium also tended to be reduced after tamoxifen treatment. However, the total amounts of $\mathrm{PGF}_{2 \alpha^{\prime}} \mathrm{PGE}_{2}$ and 6-keto-PGF ${ }_{1 \alpha}$ synthesized by homogenates of endometrium and myometrium, respectively, did not differ between the control and tamoxifen-treated guinea-pigs. This indicates that tamoxifen switches uterine PG synthesis away from $\mathrm{PGl}_{2}$ (as indicated by 6-keto- $\mathrm{PGF}_{1 \alpha}$ ) and towards $\mathrm{PGF}_{2 \alpha}$. Although there was a reduction in uterine 6-keto- $\mathrm{PGF}_{1 \alpha}$ output following tamoxifen treatment, there was no corresponding increase in $\mathrm{PGF}_{2 \alpha}$ output, although uterine $\mathrm{PGF}_{2 \alpha}$ synthesis and release was high.

The administration of ICI 182780 significantly reduced uterine horn weight by approximately $50 \%$, indicating that ICI 182780 is an anti-oestrogen in guinea-pigs. The treatment of guineapigs with ICI 182780 between days 11 and 14 of the cycle significantly reduced uterine $\mathrm{PGF}_{2 \alpha}$ output when measured on day 15. Luteolysis was therefore prevented in ICI 182780treated guinea-pigs as indicated by the high plasma progesterone concentrations. ICI 182780 , like onapristone, also reduced $\mathrm{PGE}_{2}$ output without significantly affecting the output of 6keto-PGF ${ }_{1 \alpha}$. ICI 182780 treatment also prevented the increase in endometrial $\mathrm{PGF}_{2 \alpha}$ synthesizing capacity normally observed by day 15 of the cycle, which agrees with the hypothesis that this increase is under the control of endogenous oestradiol (Poyser, 1983b). The amounts of PGE 2 and 6-keto-PGF ${ }_{1 \alpha}$ synthesized by homogenates of day 15 endometrium were also reduced by ICI 182780 , but the extents of these reductions were not as large as for $\mathrm{PGF}_{2 \alpha}$. This indicates that it is endometrial $\mathrm{PGF}_{2 \alpha}$ synthesis which is largely controlled by oestradiol. The amounts of $\mathrm{PGF}_{2 \alpha^{\prime}} \mathrm{PGE}_{2}$ and 6-keto-PGF ${ }_{1 \alpha}$ synthesized by homogenates of myometrium were unaffected by treatment with ICI 182780 . Thus, PG production by the myometrium is apparently not controlled by oestradiol.

Overall, the findings with onapristone and ICI 182780 indicate that endogenous progesterone and oestradiol are necessary for the stimulation of uterine $\mathrm{PGF}_{2 a}$ synthesis and secretion, and they support the hypothesis that oestradiol acting on a progesterone-primed uterus is the stimulus for increased $\mathrm{PGF}_{2 \alpha}$ production by the endometrium. Surprisingly, onapristone, like ICI 182780 , reduced the amounts of $\mathrm{PGF}_{2 a}$ synthesized by homogenates of the endometrium, but not of the myometrium, which suggests that in some way onapristone is also inhibiting the release or the action of oestradiol. Tamoxifen proved to be an agonist in guinea-pigs, so it had no inhibitory effect on uterine $\mathrm{PGF}_{2 \alpha}$ synthesis and release. However, tamoxifen did reduce uterine 6-keto-PGF ${ }_{1 \alpha}$ synthesis apparently by causing a switch to $\mathrm{PGF}_{2 \alpha}$ synthesis. The treatment with a pure oestrogen receptor antagonist may be beneficial in preventing an increase in uterine PG production when such an increase is not desirable, e.g. (i) in early pregnancy in non-primate mammalian species when uterine $\mathrm{PGF}_{2 \alpha}$ synthesis has not been suppressed sufficiently so that luteal function is inadequate (see Poyser, 1981), and (ii) in disorders of menstruation such as dysmenorrhoea (Lundström et al., 1976). Progesterone receptor antagonists may also have a similar use in menstrual disorders.

The technical assistance of L. Marshall is much appreciated. This study was supported by a grant from The Wellcome Trust. Onapristone was a generous gift from Schering AG, Berlin, Germany, and tamoxifen and ICI 182780 were generous gifts from ICI Pharmaceuticals, Alderley Park, Macclesfield, Cheshire, UK.

\section{References}

Antonini R, Turner TT and Pauerstein CJ (1976) The hormonal control of the guinea-pig corpus luteum during early pregnancy Fertility and Sterility $\mathbf{2 7}$ 1322-1325

Blatchley FR and Poyser NL (1974) The effect of oestrogen and progesterone on the release of prostaglandins from the uterus of the ovariectomised guineapig Journal of Reproduction and Fertility 40 205-209

Blatchley FR, Donovan BT, Horton EW and Poyser NL (1972) The release of prostaglandins and progestin into the utero-ovarian venous blood of guineapigs during the oestrous cycle and following oestrogen treatment Journal of Physiology 222 69-88

Chwalisz K, Hegel-Hartung C, Fritzemeier KH, Beier HM and Elger W (1991) Inhibition of the estradiol-mediated endometrial gland formation by the antigestagen onapristone in rabbits - relationship to uterine estrogen receptors Endocrinology 129 312-322

Earthy M, Bishop C and Flack JD (1975) Progesterone and prostaglandin F concentrations in utero-ovarian venous plasma of cyclic guinea-pigs Journal of Endocrinology $6411 \mathrm{P}-12 \mathrm{P}$

Furr BJA and Jordan VC (1984) The pharmacology and clinical uses of tamoxifen Pharmacology and Therapeutics 25 127-205

Horton EW and Poyser NL (1976) Uterine luteolytic hormone: a physiological role for prostaglandin $\mathrm{F}_{2 a}$ Physiological Reviews 55 595-651

Joshi HS, Watson DJ and Labhsetwar AD (1973) Ovarian secretion of oestradiol, oestrone, 20-dihydroprogesterone and progesterone during the oestrous cycle of the guinea-pig Joumal of Reproduction and Fertility 35 177-182

Lands WEM, LeTellier PR, Rome LH and Vanderhoek JY (1973) Inhibition of prostaglandin synthesis Advances in the Biosciences Vol. 9, pp 15-28 Ed. S Bergström. Pergamon Press, Braunschweig

Leaver HA and Poyser NL (1981) Distribution of arachidonic acid and other fatty acids in the lipids of guinea-pig uterus and plasma in relation to uterine prostaglandin synthesis Joumal of Reproduction and Fertility 61 325-333 
Lundström V, Gréen K and Wiqvist N (1976) Prostaglandins, indomethacin and dysmenorrhoea Prostaglandins 11 893-904

Mitchell S, Poyser NL and Wilson NH (1977) Effect of $p$-bromophenacyl bromide, an inhibitor of phospholipase $A_{2}$, on arachidonic acid release and prostaglandin synthesis by the guinea-pig uterus British Journal of Pharmacology 59 107-113

Poyser NL (1979) Effects of actinomycin D on uterine prostaglandin production and oestrous cycle length in guinea-pigs Joumal of Reproduction and Fertility $56559-565$

Poyser NL (1981) Prostaglandins in Reproduction John Wiley and Sons, Chichester

Poyser NL (1983a) Effect of treating ovariectomised guinea-pigs with estradiol and progesterone on basal and A23187-stimulated release of prostaglandins from the uterus superfused in vitro Prostaglandins, Leukotrienes and Medicine $11345-360$

Poyser NL (1983b) Differential stimulation of prostaglandins and thromboxane synthesising capacities in guinea-pig uterus and ovary Prostaglandins, Leukotrienes and Medicine 10 163-177

Poyser NL (1984) Prostaglandin production by the early pregnant guinea-pig uterus in relation to implantation and luteal maintenance, and the effect of oestradiol Journal of Reproduction and Fertility 72 117-127

Poyser NL (1987) Effects of various factors on prostaglandin synthesis by the guinea-pig uterus Joumal of Reproduction and Fertility 81 269-276

Poyser NL and Brydon LJ (1983) Prostaglandin release from the guinea-pig uterus superfused in vitro. Effect of stage of estrous cycle, progesterone, estradiol, oxytocin and A23187 Prostaglandins 25 443-456
Poyser NL and Horton EW (1975) Plasma progesterone levels in guinea-pigs actively immunised against prostaglandin $\mathrm{F}_{2 \alpha^{\prime}}$ hysterectomised or treated with intra-uterine indomethacin Journal of Endocrinology 67 81-88

Poyser NL and Scott FM (1980) Prostaglandin and thromboxane production by the rat uterus and ovary in vitro during the oestrous cycle Joumal of Reproduction and Fertility $6033-40$

Qing SS, Fahnrich M, Chwalisz K, Hasan HS and Elger W (1989) PGFM and sex steroid concentrations throughout the oestrous cycle and pregnancy in the guinea-pig: effects of treatment with the progesterone antagonist ZK98,299. In Hormone Antagonists for Fertility Regulation, pp 87-97 Eds CP Puri and PFA van Look. Indian SSRF, Bombay

Riley SC and Poyser NL (1987) Effects of oestradiol, progesterone, hydrocortisone and oxytocin on prostaglandin output from the guinea-pig endometrium maintained in tissue culture Prostaglandins 34 535-552

Riley SC and Poyser NL (1990) Is the inhibitory effect of progesterone on endometrial prostaglandin $F_{2 \alpha}$ production due to an inhibition of protein synthesis? Prostaglandins, Leukotrienes and Essential Fatty Acids 39 189-196

Steel RBD and Torrie JH (1980) Principles and Procedures of Statistics - A Biometrical Approach (2nd Edn) pp 106-107. McGraw-Hill Kogakusha Ltd, Tokyo

Swan CG and Poyser NL (1983) Prostaglandin synthesis by, and the effects of prostaglandins and prostaglandin analogues on, the vas deferens of the rabbit and rat in vitro Joumal of Reproduction and Fertility 69 91-99 